\title{
Cartografías de un PENSAMiento CORPORANTE: ARTE, TEATRO Y SUBJETIVIDAD DESDE G. DELEUZE http://dx.doi.org/10.1590/1984-0292/1331
}

Santiago Diaz Universidad Nacional de Mar del Plata, Mar del Plata, Buenos Aires, Argentina Universidad Nacional de Avellaneda, Avellaneda, Buenos Aires, Argentina

\section{RESUMEN}

El presente trabajo es un modo de conjugar la potencia activa del pensamiento estético deleuziano en relación con el arte, el teatro y la escritura. El cuerpo se presenta como el espacio privilegiado de creación y exploración de las sensibilidades, como un campo de batalla estético-político de las subjetividades. Así, el pensamiento corporante sería una cartografía estética de las sensaciones, donde el cuerpo conjura desde la crítica, lo lúdico y lo perverso, las insistentes formas de la identidad, de la mismidad, su armonía y su condición dogmática de capturar las fuerzas creativas.

Palabras Clave: estética; crítica; teatro; cuerpo; Deleuze.

\section{Cartography of a bodylyze thought: ART, THEATER AND SUBJECTIVITY FROM G. DELEUZE}

\begin{abstract}
The present work is a way of conjugating the effective power of Deleuzian aesthetic thought in relation to art, theater and writing. The body is presented as the privileged space of creation and exploration of sensitivities, as a field of battle of aesthetic-political subjectivities. Thus the corporealizing thought would be a cartography of aesthetic sensations, where the body conjures from critical, playful and perverse, insistent forms of identity, of sameness, its harmony and its dogmatic condition of capturing the creative forces.
\end{abstract}

Keywords: aesthetic; critique; theatre; body; Deleuze.

^ Dirección de envio: Universidad Nacional de Mar del Plata - Diagonal J. B. Alberdi 2695-

(7600) - Mar del Plata - Argentina.E-mail: ludosofia@live.com 


\section{UNA ESTÉTICA INTENSIVA, O CÓMO TRAICIONAR LA SENSACIÓN}

Es posible decir que lo estético se sostiene a partir de un mapa político de la sensación, en el cual se puede tramar un recorrido por las formas en que delinea el ethos sensible de una experiencia estética. Se trata de una constelación sensible que afecta la configuración de la subjetividad desde su presencia más íntima, desde su propio pensamiento corporante. Se puede componer una constelación en medio del desierto, pues en la lejanía inmensa de la planicie todo se vuelve cercano y familiar, un desierto menos dado por la ausencia que poblado por todas las intensidades que lo figuran. Una constelación es el diagrama trazado de afecciones que estila un recorrido por la experiencia de la cercanía, es decir un "universo de enunciabilidad". Una estética intensiva de las sensaciones no busca fundar, reconocer y verificar sentimientos preestablecidos por un dogma de la poética vigente, sino abrirse al desierto de las afecciones preindividuales, a-subjetivas y a-significantes. En este contexto, todo se vuelve un tanto diferente: la crítica pasa por una fuerza irresistible de insubordinación sustractiva que evoca una experiencia imposible; el cuerpo se expresa como una constelación móvil de afectos indiscernibles e impersonales; y la escritura se torna una trama colectiva de sentidos derivados que implican un gesto material de afección indistinguible. Este trabajo intenta ofrecer una cartografía de la las expresiones teatrales, del arte y la performance, desde la propuesta de G. Deleuze, es decir, se propone un "traz(ad)o" que delinea una curva de experimentación entre el pensamiento, el cuerpo y la escritura; una línea que diagrama su huida, esa que abre un nuevo modo de existencia (DELEUZE; PARNET, 1997, p. 45), que es una traición perversa de todo lo que subyace como fondo definido, fundamento en su más sólida concepción. Se trata de un traz(ad)o que se pinta, se percibe, se dibuja, se mueve, se compone como una sensación en tinta, una letra perceptible tan sólo por su intensidad, un alarido afónico de toda la corporalidad en fuga. Una cartografía del pensamiento corporante implica los traz(ad)os de aquellas intensidades que se tejen en una estética de la experimentación impersonal.

Traicionar las fuerzas estables que quieren retenernos, los poderes establecidos de la tierra. Lo que define el movimiento de traición es el doble alejamiento: el hombre aparta su rostro de Dios, que a su vez aparta su rostro del hombre. Y en este doble alejamiento, en la separación, en la distancia que media entre los rostros, es donde se traza la línea de fuga, es decir, la desterritorialización del hombre (DELEUZE; PARNET, 1997, p. 50).

\section{CRÍTICA, UNA EXPERIMENTACIÓN DRAMÁTICA DE LA SENSACIÓN}

Es posible pensar una crítica desde una experimentación "constituyente" de la dinámica dramática que enlaza el pensamiento y el arte (BENE; DELEUZE, 2003, p. 77), donde un operador (filosófico, artístico, etc.) diagrama recorridos intensivos a partir de la sustracción de los elementos fuertes de una obra para "hacer proliferar algo inesperado" (BENE; DELEUZE, 2003, p. 78). Si esto 
es así, el trazado crítico se propone como una "traición", una experimentación dramática que provoca movimientos aberrantes, discontinuos, querellantes, y se puede entender en un doble movimiento de huida: por intimidad perversa y por lúdico alejamiento. Aquí es donde la obra, entra en resonancia con el pensamiento y la vida, se acercan tan profundamente que activan una simbiosis heterogénea de mutua transformación; no se trata de ese pensamiento capturado por las fuerzas reactivas que lo entiende como "conocimiento", ni de la vida reducida a la materialidad equilibrada de la identidad, sino de una relación activa, plural y afirmativa, una autopoiesis, donde la vida procede como la fuerza "perversa" del pensamiento, y el pensamiento como la potencia "lúdica" de la vida. ${ }^{1}$

Una obra artística se compone a sí misma por los elementos diversos que la constituyen, cada uno de ellos cumple una función estabilizadora que colabora a tejer una trama equilibrada y homogénea de concreta representatividad. Pero en esa creación nace además la crítica, decía Blanchot (1967, p. 13), como un "espacio de resonancia" donde no se intenta capturar las fuerzas de una obra bajo la tensión estable de una interpretación sino que se busca multiplicar sus posibilidades de expresión. La crítica, en su modo creativo, traza nuevos recorridos para expresar ese rodeo que íntimamente se acerca a la obra y la pervierte silenciosamente brindándole un sentido nuevo, abierto y fresco. En efecto, la crítica pervierte, a un ritmo multiplicador, el modo de distribución sedentaria de los elementos que componen la obra. Se podría decir que provoca un recorrido "menor" por la obra, tan solo transitable en un recorrido inmanente, fuera de las formas fijas y mayoritarias que pautan las relaciones externamente. No pretende valorar su sentido evidente sino "sustraer" toda fuerza reactiva de valor que presiona su pluralidad y la encausa unitariamente bajo la jerarquización de un sentido referencial. Por ello, la crítica es una perversa variación por sustracción de todo lo que se impone como gobierno del sentido, una "perversión dramática de la sensación" (Cf. LINS, 2012, p. 202-206) que no es simplemente un modo de subvertir esquemas orgánicos de percepción, sino una operación diagramática de intensidades, productora de nuevas formas sensibles de experimentación estética, la cual puede ser entendida como una forma de resistencia a los dominios de gobierno de la experiencia. ${ }^{2}$

La crítica como una expresión dramática comporta un teatro "especial”, una dramática filosófica que toma del teatro toda su dinámica y potencia fabuladora, lo que permite diagramar una travesía filosófica que poco tiene que ver con las grandes historias y los conceptos universales, sino -como decía Foucault- que toda empresa crítica sea de algún modo una apuesta por "pervertir" el platonismo, un descentramiento del modelo, de lo idéntico, de lo mismo, de lo armónico y equilibrado. Entonces, la crítica se piensa como una forma de pervertir toda filosofía, todo pensamiento desde el deslizamiento por lo subyacente hasta instaurar "otra serie desatada y divergente" (FOUCAULT; DELEUZE, 1995, p. 11). Se trata de un "juego epidérmico de la perversidad", que desata los gestos indecibles, una transgresión en la pluralidad de escenas que se fragmentan para multiplicar efectos sin referencialidad, es "el teatro multiplicado, poliescénico, 
simultaneado, fragmentado en escenas que se ignoran y se hacen señales, y en el que sin representar nada (copiar, imitar) danzan máscaras, gritan cuerpos, gesticulan manos y dedos" (FOUCAULT; DELEUZE, 1995, p. 15).

Deleuze interviene filosóficamente el teatro de Carmelo Bene, y aporta la noción de crítica como una forma de operativa de "minoración" sobre los elementos de Poder que dominan una obra teatral. Esta operación "menor" hace bascular la obra tradicional por espacios inimaginables, la hace girar sobre sí misma para "posarse sobre otro costado" (BENE; DELEUZE, 2003, p. 77). El autor se aleja de su obra, porque ya no le pertenece, y con esto él mismo es vuelve un síntoma que produce y distribuye una constelación de afecciones. Su nombre no es más que un bloque de sensaciones en constante devenir: "Deleuze" es una constelación de conceptos que, como personaje filosófico, trama una serie de procedimientos de minoración sobre la historia de la filosofía, la literatura y el arte. Introduce devenires que hacen oscilar por tierras ajenas la vida conceptual de Spinoza, de Bergson, de Proust, de Kafka o Bacon, entre otros. Con Bene, el tratamiento menor se presenta en forma de "sustracción", como un modo operativo del autor, aunque en este caso el autor no es más que un personaje que articula los elementos de la obra; es el "escritor" que minoriza las relaciones mayoritarias de una obra cuando traza e inventa nuevos agenciamientos (DELEUZE; PARNET, 1997, 61), y los hace funcionar en otro juego, los hace pasar intensamente por ese umbral que es el autor. Así, la crítica no trata de juzgar la importancia de una obra o valorar la posición destacada en la historia que ésta institucionalmente merece, sino que intenta "sustraer" toda valoración que fije su potencia creativa para abrir sus expresiones a una multiplicidad como efecto disparador de una experimentación densa, polifónica, multitudinaria: un teatro-experimentación, una poesía de las intensidades, una dramática filosófica.

No puedo dejar de pensar en una crítica que no buscara juzgar, sino hacer existir una obra, un libro, una frase, una idea. Una crítica así encendería fuegos, contemplaría crecer la hierba, escucharía el viento y tomaría la espuma al vuelo para esparcirla. Multiplicaría no los juicios, sino los signos de existencia; los llamaría, los sacaría de su sueño. ¿Los inventaría en ocasiones? Tanto mejor, mucho mejor. La crítica por sentencias me adormece. Me gustaría una crítica por centelleos imaginativos, no sería soberana ni vestida de rojo. Llevaría el relámpago de las tormentas posibles (FOUCAULT, 1999, p. 220).

Siguiendo lo que Deleuze le escribió a Arnaud Villani en 1984 (Cf. PELLEJERO, 2005, p. 34), la crítica lucha un combate contra lo instituido, pero esa lucha no devela un combate demoledor sino una derivada, una lucha que aumenta y no disminuye las relaciones, que suma a la obra una nueva cara, un sentido inesperado, una voz que subyace silenciosa y arranca de ella un grito incomprensible. La crítica busca hacer existir otra obra, hacerla huir por líneas de fuga, líneas que al derivar en otro mundo, provoquen una experiencia sensible distinta; ahí lo 
perverso de la crítica que en su dramática diferenciación inmanente suprime "lo indiferenciado que se divide en ella, ese suspenso que marca cada momento de la diferencia, esta inmovilización que marca cada momento de la caída" (DELEUZE, 1994, p. 281-282). La crítica no puede preguntarse por la esencia de una obra, tan sólo pueda dar lugar a una experimentación abierta de la (in)actualidad que porta; la crítica establece una pregunta por lo "nuevo" (PELLEJERO, 2005, p. 213), que desestabiliza todo interés mayoritario por hacer del pensamiento una Doctrina, de una manera singular de vivir una Cultura, de cualquier acontecimiento una Historia (BENE; DELEUZE, 2003, p. 83). En definitiva, si la crítica es esa fuerza irresistible de insubordinación sustractiva, de perversión sensible, lo es porque en su movimiento "dramático" (DELEUZE, 2007, p. 192) hace devenir la filosofía, la literatura, el arte en un pensamiento vital de la experimentación estética que se evoca bajo una apertura múltiple de lo nuevo.

\section{EL CUERPO, UNA TERRITORIALIDAD PERVERSA DE LAS INTENSIDADES AFECTIVAS}

En verdad, un orden de perversión ha hecho estallar el orden divino de la integridad: perversión en el mundo de aquí abajo, donde reina una tempestuosa naturaleza exuberante, llena de violaciones, de estupros y de transvestimientos, puesto que son varias almas las que entran en un mismo cuerpo, y que una sola alma posee varios de ellos; perversión de allá arriba, puesto que los alientos ya en sí mismos se mezclan. ¡Dios ya no puede garantizar ninguna identidad! (DELEUZE, 1994, p. 293).

El cuerpo es quien posee esa potencia propia que le permite mantener, y producir, la instancia creativa de la perversión en el momento en que genera una distribución "nómada" de sus elementos, será el caso del "cuerpo sin órganos", como límite intensivo de la organización jerárquica de los órganos, que comportará una expresión perversa. "La perversión, [dice Deleuze], es la potencia activa del cuerpo" (DELEUZE, 1994, p. 282), un cuerpo larvario, que establece una dramática (in)orgánica en un "spatium" intensivo donde se fluctúa entre las singularidades pre-individuales y las individuaciones impersonales (el esplendor de SE - DELEUZE, 2009b, p. 18-). Es un cuerpo intenso que sostiene activamente esa indiferenciación en la variación afirmativa de las relaciones (DELEUZE, 2005, p. 130-133), lo que permite dirigir las tendencias relacionales que posibilitan el mantenimiento de las mutaciones diferenciales. Se trata de trazar, en una región de actividad indiferenciada, la pluralidad de ondas de variación que producen la potencia creativa de un cuerpo, que no se piensa sino como un umbral intensivo de fuerzas (DELEUZE, 2002, p. 47). Esto puede verse en la embriología, donde el huevo, como medio intenso de materias no formadas, establece un plano de consistencia que actualiza "un campo problemático virtual, intensivo y real en individuos diferenciados" (SAUVAGNARGUES, 2006, p. 47). 
La perversión es la potencia insistente de una incertidumbre que sostiene cierta experimentación de fuerzas imperceptibles, anónimas y extranjeras, las cuales no delimitan el cuerpo sino que lo fuerzan a trazar un nuevo recorrido por sus travesías vitales, por sus individuaciones impersonales, o mejor a sostener su embriología germinal. La perversión del cuerpo es la potencia de una "vida no orgánica" (DELEUZE, 2009a, p. 183) que brota rizomáticamente en medio no sólo de los organismos, sino también del pensamiento, y hace crecer su condición creativa como el resultado fortuito, como dice Klossowski (2009, p. 38), "de un conjunto de impulsos individuales por ese intervalo que constituye una vida humana, pero que no aspiran más que a "desindividuarse"". Esto es lo que se podría denominar la perversión no orgánica del cuerpo como "Heterogénesis Autopoiética". Es decir, una distribución nómade que despliega un diagrama de criterios momentáneos y autoregulados, y que acciona operadores de transversalidad anárquica, de grupuscularidad, de molecularización, de minoración y de desterritorialización sensible de las afecciones. Entonces el cuerpo se transforma en una máquina "abstracta" de exploración, conexión y producción relacional, en tanto multiplicidad activa de vitalidad inorgánica, que traza una alianza perversa entre el pensamiento, el arte y la vida. Una alianza "contranatura [que pretende] convertir el cuerpo en una fuerza que no se reduzca al organismo, [tanto como] convertir el pensamiento en una fuerza que no se reduzca a la conciencia" (DELEUZE; PARNET, 1997, 72), ${ }^{3}$ donde ya no se sabe si es la pantomima la que piensa o el pensamiento quien gesticula (DELEUZE, 1994, p. 281). Esto en la voz dramática de Nietzsche (2008, p. 53) es que "por debajo de cada pensamiento se esconde un afecto" al igual que todo acto de pensamiento afirma una potencia afectiva de transvaloración.

Ciertamente, un cuerpo es perversamente crítico en sus formas experimentales de configurar nuevas experiencias sensibles, abiertas y polifónicas. El cuerpo no es una unidad orgánica que sintetiza las experiencias sino una multiplicidad inmanente y relacional que excede los límites sensibles de los órganos compositivos. En este sentido, se puede pensar en un cuerpo sólo en el momento en que se abren conexiones a-paralelas, trazados inciertos de afectos, redes fluctuantes de conceptos. Un cuerpo es crítico en ese instante donde se tiende hacia la pluralidad de lo nuevo, sus contorciones y flexiones (DELEUZE, 1994, p. 286) lo transforman en cada giro brusco de su propio descentramiento, como la serpiente emplumada que diverge entre las culturas multinaturales del pasado amerindio (Cf. VIVEIROS DE CASTRO, 2010, p. 25 et seq.).

El cuerpo se mueve flexiblemente como un trazo continuo que dibuja una línea quebrada, de huida y creación vital; entonces la escritura posee un cuerpo que rodea entre flexiones y gesticulaciones la sombra de lo abierto, su nebulosa neutralidad se vuelve intensiva en los márgenes de su densidad. Cuerpo y escritura, un traz(ad)o de intensidades que abre un mapa de experimentaciones estéticovitales. Rasgar todo plano con un gesto impregnado de huidas, vaciar el cuerpo de sentido y desprender sus seguras cavidades, sus puntos de apoyo, sus sostenidas firmezas. Puntos flotantes y todo se desliza como el movimiento sensible de una escritura que provoca en sí misma la potencia múltiple de un desahogo incesante. Y 
el cuerpo se mueve en esa escritura crítica, perversa, lúdica, que vuelve estética, es decir creativa, toda forma de pensamiento, y su tensión se abre al juego afirmativo del azar y la perversa inquietud de una existencia impersonal.

En efecto, el cuerpo se escribe perversamente en los signos de un juego y una lucha de afectos, como dice Nietzsche, unidos por raíces ocultas (NIETZSCHE, 2008, p. 55), que convergen en un agón fulgurante de fuerzas en tensión. El cuerpo no deja de "preducir"4 su propia minoración, al desprender de sí toda sistemática mecánica, toda dogmática de los esquemas sensorio-motores que reducen el movimiento al espacio tanto como el tiempo a una sucesión estatificada de segmentos identitarios. Basta con referirnos al teatro bunraku ${ }^{5}$ o a la danza butoh ${ }^{6}$, donde un cuerpo "fragmentario" se desplaza y dirige a partir de un nuevo mundo de movimientos aberrantes, de gestos a-significantes, de traz(ad)os impersonales. Toda la potencia de un instante volcada en el gesto mínimo de un movimiento imperceptible. Una proliferación de universos de enunciabilidad que producen devenires intensos en el recorrido vibrante de un gesto inamovible, espectros subyugantes de las formas sensibles que se desprenden de toda referencialidad para estallar en cuerpos impredecibles. La danza butoh produce cuerpos que devuelven una distribución inorgánica de la vida, donde no hay centro, ni punto de referencia, tan sólo un espacio abierto a la pluralidad intensiva de las fuerzas que se cruzan:

[...] Los cuerpos ya no tienen centro, salvo el de su muerte, cuando se agotan y se reúnen con la tierra para disolverse en ella. La fuerza ya no tiene centro precisamente porque es inseparable de su relación con otras fuerzas [...] (DELEUZE, 2009c, p. 192).

La inversión filosófica, entonces, es trazar en el pensamiento un cuerpo, es decir, una dramática perversa de los conceptos. El cuerpo en su pluraliversalidad fuerza a pensar lo impensado. Cada movimiento de pensamiento es un gesto corporante de acercamiento a la vida no orgánica que soporta la potencia creativa de un cuerpo. No se trata, dice Deleuze, de hacer comparecer la vida ante las categorías del pensamiento sino de arrojar el pensamiento a la inmanente intensidad de la vida. Por eso, "pensar es aprender lo que puede un cuerpo no pensante, su capacidad, sus actitudes y posturas" (DELEUZE, 2009c, p. 251). Es por el cuerpo (y ya no por intermedio del cuerpo) que la filosofía y el arte co-existen como el germen vital del pensamiento (DELEUZE, 2009c, p. 231). Se trata de devolver al cuerpo su voz, un gesto sonoro que "hace audibles fuerzas que no lo son", y alcanzar ese discurso anterior al cuerpo organizado, anterior a las palabras, anterior al nombramiento: el "nombre", antes del nombre (DELEUZE, 2009c, p. 231), y abrir el umbral intenso y productivo de los universos de enunciabilidad que solo expresan intensidades.

El cuerpo-escritura excede la representación, la significancia y toda forma de referencialidad; expresa el acontecimiento que se sitúa en la superficie de las cosas, roza asintóticamente el mundo y le da un sentido evanescente, el lenguaje de un pensamiento corporante, a-significante e impersonal. Esto es la cascada de 
palabras que obliga a "estar en soledad como charla incesante" en la desintegración orgánica de un cuerpo fragmentario que aparece en los Happy days beckettianos; esto es ese "lenguaje nativo" de Amanda Baggs ${ }^{7}$ o el rostro transfigurado de Olivier de Sagazan. ${ }^{8}$ Así, la escritura corporante se elabora como un traz(ad)o lúdico de lenguaje inasible, incluso vacilante, de la expresión impersonal. Esa escritura es una estética lúdico-perversa de lo fragmentario que hace huir lo personal, lo significante, lo orgánico, de toda forma dogmática y jerárquica de los modos de existencia. En definitiva, se trata de pensar la potencia intensiva de la perversión del cuerpo bajo la expresión de una escritura lúdico-fragmentaria.

\section{Tramar las SENSACIONES, UNA ESCRITURa LÚdico-Fragmentaria}

“...escribir es una tentativa de convertir la vida en algo que no es sólo personal, de liberar

la vida de aquello que la aprisiona."

(DELEUZE, 1999, p. 228).

Nietzsche amaba lo escrito con el espíritu, o sea con la sangre(NIETZSCHE, 2000, p. 73), un cuerpo-lenguaje que fluye en esa turbia tendencia de las palabras que no recorren un sentido, sino bajo la sombra de una máscara: "toda filosofía esconde también una filosofía; toda opinión es también un escondite, toda palabra, también una máscara" (NIETZSCHE, 1999, p. 264), decía entre líneas. El problema de escribir es hacer delirar la lengua hacia ese límite de lo indecible (DELEUZE, 2009a, p. 9), como el afuera productivo de esos procesos que trazan el diagrama de criterios orientativos de una nueva experimentación sensible, una travesía que recorre sus trayectos intensivos como un paisaje sombrío y nunca antes visitado. Escribir es el diagnóstico delineado de una experiencia que tiende a lo impersonal, "hacer ver y entender, visiones y audiciones no lingüísticas" (Cf. MENGUE, 2008, p. 421) es atravesar con una intensa línea a-subjetiva y a-significante la vida personal, para hacer brotar en su carne y en su letra toda la fuerza vital del "afuera". Las letras se inscriben en la ebullición íntima de la sangre, como materialidad fluida de la corporalidad; un balbuceo intermedio que brota del ahogo del lenguaje y de la expresión corporal, el balbuceo que juega con el lenguaje entre el decir superficial y la profundidad gutural de aquello que mil veces se dice en el instante que se calla (DELEUZE, 2009a, p. 154). ${ }^{9}$ El balbuceo atraviesa el cuerpo como creación lúdica de las entonaciones expresivas, un respiro de estados puramente intensivos, así como el tartamudeo no deja de producir la repetición diferencial del lenguaje, un cuerpo-lenguaje perverso y lúdico, porque "el poder de las palabras llega a su punto culminante cuando dirige la repetición de los cuerpos". ${ }^{10}$ Como Whitman convocó las granulaciones fragmentarias que modulan el intervalo de las palabras (DELEUZE, 2009a, p. 84), el teatro bunraku los gestos neutros de un movimiento inorgánico, y la música electroacústica alcanza ese instante donde el rodeo por el sonido no es sino la pura materialidad impersonal de la música: la escritura, esa voz plural de los sensible, como acto de fragmentariedad, traza un diagrama multilineal de sentidos, tejiendo en su densidad los cuerpos -aquellos "cuerpos colectivos" de Lygia Clark ${ }^{11}$ - para abrirlos a la experimentación sensible de sus relaciones 
más inciertas, más inesperadas. En este caso, lo fragmentario provoca un mundo discontinuo que se vuelve pluralidad de fuerzas en tensión diferencial, no ya un mundo-objeto y un mundo-sujeto, ${ }^{12}$ sino una "pluriversalidad" lúdica y a la vez perversa de fuerzas que fluctúan y se diferencian en un repetirse afirmativamente de sus conexiones intensivas. No se trata de un sentido fragmentario disminuido detrás de la cerrada esperanza de encontrar un cierto equilibrio a lo escrito, ni pensarlo como carente de la confiada lógica "lineal" "l3 de la referencialidad, sino que su fragmentaria expresión más que inestabilidad nos "promete el desconcierto, el desacomodo" (BLANCHOT, 1990, p. 14) incierto de lo nuevo. ${ }^{14}$ Pensar, dice Foucault, ni consuela ni hace feliz (FOUCAULT; DELEUZE, 1995, p. 41). Entonces, lo fragmentario atraviesa lo orgánico de la escritura para abrir la conexión aleatoria de las singularidades que pueblan el mundo, y el cual se presenta como una colección levemente sostenida de granulaciones heterogéneas: "que efectúa toda la potencia de bifurcación y de variación, de heterogénesis y modulación propia de la lengua" (DELEUZE, 2009a, p. 152). La escritura fragmentaria no puede ser una totalidad que se distribuye en partes, sino que mantiene esa pluralidad en una puesta en relación de esos heterogéneos singulares, o mejor, es la invención de relaciones, un camino embrollado de resonancias que permite las afecciones donde no importa la procedencia, ni el origen, ni el linaje: pura asamblea de la naturaleza. ${ }^{15}$

Efectivamente, la escritura lúdico-fragmentaria puede ser entendida como una "diagramática" de máquinas abstractas (DELEUZE; GUATTARI, 2010, p. 144), que ignora las distancias entre el cuerpo y la escritura, que excede las palabras y se traza en una corporalidad de entonaciones para dar vida a sus expresiones sensibles impersonales. La escritura lúdico-fragmentaria es la potencia corporal del lenguaje que se traza en las palabras como músculos tensionados en pleno acto deportivo: el atletismo del concepto no es sino la expresión no-orgánica de la filosofía, o el vitalismo impersonal que se traza en la diagonal entre el pensamiento y la vida. "Un Atletismo que no es orgánico o muscular, sino 'un atletismo afectivo', que sería el doble inorgánico del otro, un atletismo del devenir que revela únicamente unas fuerzas que no son las suyas, "espectro plástico" (DELEUZE; GUATTARI, 2009, p. 174). Se trata de un continuum tan intenso que desborda la vida geométrica de la percepción cotidiana, excede sus referencias, las supera y fuerza a experimentar otro modo de existencia. Los artistas que vuelven con los ojos enrojecidos por la videncia de esa experiencia que los desborda, que arrebata su experiencia de vida, una experiencia siempre pasada y sedimentada. Su debilidad es la enfermedad que les hace ver, sentir y accionar en un estado indiscernible entre la salud y la enfermedad (de abolición), es una zona enfermiza donde el cuerpo vibra en tonos inarmónicos, melodías crispadas, el ruido sensible o la "densidad clara". ${ }^{16}$

"Tienen a menudo una salud precaria y demasiado frágil, pero no por culpa de sus enfermedades ni de sus neurosis, sino porque han visto en la vida algo demasiado grande para cualquiera, demasiado grande para ellos, y que los ha marcado discretamente con el sello de la muerte." (DELEUZE; GUATTARI, 2009, p. 174). ${ }^{17}$ 
En el teatro de Bob Wilson, se procede por esta enfermedad de los sentidos, una forma de anti-terapia o terapéutica anómala, que no pretende normalizar las experiencias dramáticas de los espectadores, cierta catarsis individualizante, sino "enfermarlos" (VALENZUELA, 2004, p. 62) de experiencias imposibles y colectivas. Dice Deleuze (2009b, p. 18, las cursivas son del autor) en Diferencia y Repetición:

¿Cómo hacer para escribir si no es sobre lo qué no se sabe, o lo que se sabe mal? Es acerca de esto, necesariamente, que imaginamos tener algo que decir. Sólo escribimos en la extremidad de nuestro saber, en ese punto extremo que separa nuestro saber y nuestra ignorancia, y que hace pasar el uno dentro de la otra. Sólo así nos decidimos a escribir. Colmar la ignorancia es postergar la escritura hasta mañana, o más bien volverla imposible.

\title{
Traz(AD)OS DE UN PENSAMIENTO CORPORANTE
}

\author{
"Toda obra es un viaje, un trayecto, pero que \\ sólo recorre tal o cual camino exterior en virtud \\ de los caminos y de las trayectorias interiores que \\ la componen, que constituyen su paisaje o su concierto."
}

(DELEUZE, 2009a, p. 10).

De la crítica como experimentación dramática de lo sensible, y el cuerpo como intensa perversión relacional de las singularidades pre-individuales, a la composición lúdico-fragmentaria de la escritura, todo se desliza por una estética lúdico-perversa que se trama en el cuerpo traz(ad)o, a partir del cual se efectúa el umbral de resonancia por donde pasa y se multiplica el "pensamiento corporante" (Cf. KLOSSOWSKI, 2009, p. 41) de la vida no orgánica. Como dice Foucault, "cuando el azar, el teatro y la perversión entran en resonancia, cuando el azar quiere que entre los tres haya esta resonancia, entonces el pensamiento es un trance; y entonces vale la pena pensar" (FOUCAULT; DELEUZE, 1995, 41).

Un pensamiento de lo múltiple que se expresa en tensiones inquietantes con todas las fuerzas que lo contienen e impulsan en un espacio infinitamente veloz por la intensidad de los afectos que lo recorren. Este "plateaux" intensivo de anónima creación no hace más que hacer sensible esa tierra extranjera, que no es sino el "afuera" del pensamiento. Quizás no sea necesario decir que el cuerpo piensa, pero indudablemente es aquello que "obstinado, terco, él fuerza a pensar, y fuerza a pensar lo que escapa al pensamiento, la vida" (DELEUZE, 2009c, p. 251). Así, la crítica se vuelve el modo de experimentación plural donde el cuerpo pervierte toda sensación y produce una dramática nómada de lo sensible; y la escritura permite ese deslizamiento lúdico por la experiencia fragmentaria de lo vital. Así, el arte, el pensamiento y la vida se conectan para generar esa zona de indiscernibilidad donde no hay más que gestos múltiples y pluriversales de sentidos infinitamente diversificados, "dispares". Entonces el 
pensamiento, el arte y la vida se vuelven a un teatro de mimos, performance cruel y perversa, de un juego con escenas múltiples y fugitivas, instantáneas, donde los gestos, sin verse, se afectan en la materialidad más intensa de lo impersonal (Cf. FOUCAULT; DELEUZE, 1995, p. 47). Es la filosofía "no como pensamiento, sino como teatro", donde el pensamiento se vuelve traz(ad)o corporante.

Estos traz(ad)os del pensamiento corporante provocan series discontinuas de tensiones fragmentarias, que se dan en una lucha, en un agón que se tiende desde la risa, el olvido, y la inocencia del "niño" nietzscheano, un acto de simple transvaloración. Es un combate comprometido con las resonancias que se libra sobre la cartografía de un pensamiento de las sensaciones, y que se lanza a una lucha no ya "en contra" de las representaciones, las identidades y la armonía de la experiencia sensible - esa lucha "exterior" y trascendente-, sino que se dedica a librar una "lucha-entre", una lucha inmanente que "determina la composición de las fuerzas en el luchador" (DELEUZE, 2009a, p. 184). Si pensamos la crítica como guerra contra la injustica, la falsedad y lo diferente, contraemos esa voluntad de destrucción divina que proclama para sí la verdad, el bien y sus derivados. El cuerpo nos trae la pluralidad revolucionaria de una experiencia natural de la multiplicidad y la escritura no es más que ese traz(ad)o corporante que brinda la lucha inmanente que enriquece, "apoderándose de otras fuerzas y sumando en un nuevo conjunto, en un devenir" (DELEUZE, 2009a, p. 184). En definitiva, el traz(ad)o de un pensamiento corporante es el combate estético -lúdico y perverso- que despliega activamente la "heterogénesis" de una vitalidad no orgánica y que potencia el juego impersonal de las afecciones en un devenir incesante y colectivo de resistencia a todo lo orgánico, identitario y totalizante (DELEUZE, 2009a, p. 186; Cf. GORLIER, 2011, p. 33).

Crear no es comunicar sino resistir. Hay un profundo vínculo entre los signos, el acontecimiento y la vida, el vitalismo. Es la potencia de una vida no orgánica, la que puede tener lugar en la línea de un dibujo, en una línea de escritura o de música. Los organismos mueren, pero no la vida. No hay obra que no deje a la vida una salida, que no señale un camino entre los adoquines. Todo cuanto he escrito -al menos así lo esperoha sido vitalista [...] (DELEUZE, 1999, p. 229). 


\section{Notas}

${ }^{1}$ Nos remitimos a la idea de que la vida es la fuerza activa del pensamiento, así como el pensamiento el poder afirmativo de la vida. Cf. Deleuze (2008, p. 143).

2 "La critique ne doit pas être entendue comme un discours plus ou moins subversif sur la société mais comme création de nouvelles formes cinématographiques qui font de l'esthétique une discipline de la résistance." (HÊME DE LACOTTE GILLES, 2003, p. 127).

3 "Hacerse un cuerpo sin órganos, encontrar el propio cuerpo sin órganos es la manera de sustraerse al juicio" (DELEUZE, 2009a, p. 182)

${ }^{4}$ Conjunción entre producir y educir, entendiendo la coimplicancia de lo lúdico y lo perverso como algo diferente de la "producción", en la cual se mantiene una relación de posproducción que sigue interviniendo, de manera inmanente, en lo educido. Como un continuum intensivo, esa embriología germinal que no deja que lo individuado se pierda en la petrificación de sus virtualidades.

${ }^{5}$ Ningyō jōruri (marionetas e historias contadas)

${ }^{6}$ Cf. Performance del Imre Thormann en el templo de Hiyoshi Taisha en Shiga (Japón), realizada en el verano de 2006. La música en vivo a cargo del pianista de jazz Nik Baertsch y su banda "Mobile" http://www.youtube.com/watch?v=9ms7MGs2Nh8

${ }^{7}$ Amanda Baggs, "In my language". http://www.youtube.com/watch?v=JnylM1hI2jc Cf. DELEUZE, 2009a, p. 89-97; 150-159.

${ }^{8} \mathrm{http}: / /$ vimeo.com/8623092

${ }^{9}$ Cf. Ghérasim Luca, "Passionnément". http://www.youtube.com/watch?v=161tchO5Vpw

${ }^{10} \mathrm{SMS}, 17$

${ }^{11}$ Cf. "Baba antropofágica" http://www.youtube.com/watch?v=ynq7JMXvWvA

12 "No se trata de subjetivismo, puesto que plantear el problema en estos términos de fuerza, y no en otros términos, supera ya cualquier subjetividad." (DELEUZE, 2009a, p.188)

13 "No hay líneas rectas, ni en las cosas ni en el lenguaje. La sintaxis es el conjunto de caminos indirectos creados en cada ocasión para poner de manifiesto la vida en las cosas." (DELEUZE, 1999, p. 12-13)

14 "Por doquier las relaciones de contrapunto están por inventar y condicionar la evolución" (DELEUZE, 2009a, p. 87)

15 "La Naturaleza no es forma, sino proceso de puesta en relación: inventa una polifonía, no es totalidad, sino reunión, 'cónclave', ‘asamblea plenaria'.” (DELEUZE, 2009a, p. 86)

${ }^{16}$ Referencia a un concepto que utiliza Munch, sonidista de Coppola en Apocalipsis Now.

${ }^{17}$ Cf. DELEUZE, 1999, p. 228-229 


\section{REFERENCES}

APOCALYPSE Now. Director: Francis Ford Coppola. San Francisco, USA: Zoetrope Studios, 1979. 1 DVD.

BENE, C.; DELEUZE, G. Superposiciones. Buenos Aires: Artes del Sur, 2003.

BLANCHOT, M. Sade y Lautréamont. Buenos Aires: Mediodía, 1967.

BLANCHOT, M. La escritura del desastre. Caracas: Monte Ávila, 1990.

DELEUZE, G. Lógica del sentido. Barcelona: Planeta-De Agostini, 1994.

DELEUZE, G. Conversaciones 1972-1990. Valencia: Pre-Textos, 1999.

DELEUZE, G. Francis Bacon: lógica de la sensación. Madrid: Arena Libros, 2002.

DELEUZE, G. La isla desierta y otros textos: textos y entrevistas (1953-1974). Valencia: Pre-Textos, 2005.

DELEUZE, G. Dos regímenes de locos: textos y entrevistas (1975-1995). Valencia: Pre-Textos, 2007.

DELEUZE, G. Nietzsche y la filosofía. Barcelona: Anagrama, 2008.

DELEUZE, G. Crítica y clínica. Barcelona: Anagrama, 2009a.

DELEUZE, G. Diferencia y repetición. Buenos Aires: Amorrortu, 2009b.

DELEUZE, G. La Imagen-Tiempo: estudios sobre cine 2. Buenos Aires: Paidós, 2009c.

DELEUZE, G.; GUATTARI, F. ¿Qué es la filosofia? Barcelona: Anagrama, 2009.

DELEUZE, G.; GUATTARI, F. Mil Mesetas: capitalismo y esquizofrenia. Valencia: Pre-Textos, 2010. v. 2.

DELEUZE, G.; PARNET, C. Diálogos. Valencia: Pre-Textos, 1997.

FOUCAULT, M. El filósofo enmascarado. En: Estética, Ética y Hermenéutica. Barcelona: Paidós, 1999. Obras Esenciales, v. 3, p. 217-224.

FOUCAULT, M.; DELEUZE, G. Theatrum Philosophicum seguido de Repetición $y$ diferencia. Barcelona: Anagrama, 1995. 
GORLIER, J. C. Nudos del lenguaje: cuerpo, escritura, voz. Mar del Plata: Eudem, 2011.

HÊME DE LACOTTE GILLES, S. Deleuze et la critique. En: Mouvements, [S.1.], v. 3, n. 27-28, p. 126-131, 2003.

KLOSSOWSKI, P. Nietzsche y el círculo vicioso. La Plata: Terramar, 2009.

LINS, D. Estética como acontecimento o corpo sem órgãos. São Paulo: Lumme, 2012.

MENGUE, P. Deleuze: o el sistema de lo múltiple. Buenos Aires: Las Cuarenta, 2008 .

NIETZSCHE, F. Más allá de bien y del mal. Barcelona: Altaya, 1999.

NIETZSCHE, F. Asi habló Zaratustra. Madrid: Alianza, 2000.

NIETZSCHE, F. Fragmentos Póstumos (1885-1889). Madrid: Tecnos, 2008. v. 4.

PELLEJERO, E. Deleuze y la redefinición de la filosofia: apuntes desde la perspectiva de la inactualidad. 2005. Tesis (Doctorado)-Universidad de Lisboa, Lisboa, 2005.

SAUVAGNARGUES, A. Deleuze: del animal al arte. Buenos Aires: Amorrortu, 2006.

VALENZUELA, J. L. Robert "Bob" Wilson: la locomotora dentro del Fantasma. Buenos Aires: Atuel, 2004.

VIVEIROS DE CASTRO, E. Metafísicas caníbales: líneas de antropología postestructural. Buenos Aires: Katz, 2010.

Recibido: 02 de julio 2014 Aceptado: 03 de septiembre 2014 